\title{
Qual é o EFeito dAs EXPERIÊNCIAS de AprendizAGEM QUE Propomos aos Nossos Alunos?
}

\author{
MARIA GoretI*
}

Os últimos estudos PISA terão feito (re)lembrar a importância do ensino experimental das ciências, e estarão na base da publicação do Despacho n. ${ }^{\circ}$ 2143/2007 de 09 de Fevereiro, do Ministério da Educação, onde pode ler-se:

"Aeducação científica de base assume um papel fundamental na promoção da literacia científica, potenciando o desenvolvimento de competências necessárias ao exercício de uma cidadania interveniente e informada e à inserção numa vida profissional qualificada. Entre os factores que contribuem de forma decisiva para o desenvolvimento destas competências, salienta-se a importância de iniciar nos primeiros anos de escolaridade o ensino das ciências de base experimental, de forma a estimular a curiosidade e o interesse das crianças pela ciência (..).

Os resultados de estudos internacionais revelam que os alunos portugueses têm, em média, um desempenho na área da literacia científica significativamente inferior ao da média dos países da OCDE, não se verificando melhorias apreciáveis nos últimos anos."

Continuar a promoção da literacia científica através dos conteúdos da componente de Química, que são contemplados nos programas actuais a partir do $10 .^{\circ}$ ano de escolaridade, deveria ser consequente de um trabalho previamente desenvolvido no âmbito de temáticas curriculares de anos anteriores, ou não?

Entendo que dessa promoção deveria resultar, também, uma maior capacidade dos alunos para interpretar objectos e/ou informações do seu quotidiano imediato, mas...

\footnotetext{
Professora de Física e Química nas Oficinas de S. José, Associação Educativa
}

Fico preocupada quando verifico que muitos dos alunos não encontram nenhuma relação entre as aprendizagens conseguidas em sala de aula, e tão simplesmente a sua aplicação ao que... comem, bebem, respiram... Fico assustada quando percebo como são tão ágeis a memorizar fórmulas e definições de concentrações, mas revelam fragilidades enormes quando solicito uma análise interpretativa de informação de rótulos de produtos alimentares, por exemplo. Se pensar na dificuldade na interpretação de realidades mais complexas, e no relacionamento com aprendizagens em outras disciplinas, então o susto será maior!

O que é que está a falhar? As experiências de aprendizagem que proporcionamos aos nossos alunos? $\mathrm{Na}$ forma como as apresentamos, nas metodologias que usamos, nos materiais e ou nos conteúdos envolvidos? A verdade é que parece existir um divórcio entre o que se aprende na componente de Química e a realidade, não obstante alguns conteúdos a leccionar mais parecerem apenas contexto...

Começo a pensar que os ácidos, as bases, os sais, e tudo o que mais lhes colocamos à frente, em tabuleiros muito bem preparados, de nada valem... No final só resta a preocupação pelo formulário, pela memorização, pela resolução mecanizada de exercícios já feitos e refeitos sem análise de processos e de resultados... pois operar de outra forma, sobre os objectos do seu conhecimento, dá muito trabalho e é difícil! Mas...

Eu sempre fui crítica relativamente às propostas de materiais a usar nas actividades laboratoriais propostas para o secundário! Se estão longe da vida dos alunos, que efeito de despertar necessidades de atenção mais profunda sobre o que os rodeia podem ter? Acredito que uma das formas de promover o desenvolvimento de competências é gerar nos alunos necessidades de operar e intervir, de forma responsável e consciente, analisando, discutindo, planeando, resolvendo... para encontrar (ou não) respostas. $E$ isso não se consegue, exclusiva e necessariamente, à custa de químicos que os alunos não podem saborear, moldar, cheirar... Entendo que a promoção da literacia científica não pode estar dependente de protocolos e químicos já feitos, e que apenas exigem dos alunos um comportamento robotizado como se eles fossem desprovidos de mente capaz de operar.

Não tenho receitas, não conheço muitos caminhos, e cada tentativa diferente é uma ida à descoberta. A minha última tentativa assumiu a forma de uma interrogação colocada a cada um dos alunos de uma turma do $10^{\circ}$ ano, como por exemplo: Qual é a percentagem de água numa abóbora? Numa maçã, numa cenoura..... De Setembro a Janeiro era tempo de pensar, planear, fazer, descobrir, interpretar... para além da aula. O resultado de um dos alunos é apresentado a seguir.

Quais foram os resultados na aprendizagem? Não os procuro no imediato, este é o início de um caminho, e procurar resultados imediatos em educação é assumir a derrota à partida... 


\section{Aprendendo com uma abóbora Ana Mafalda Silva $\mathrm{N}^{\circ} 10^{\circ} \mathrm{T} 2$}

Esta experiência teve como objectivo, calcular a percentagem de água existente numa abóbora.

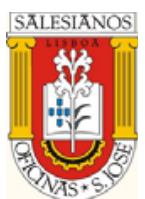

Oficinas de S. José Associação Educativa

A abóbora é um legume alaranjado, que nasce da aboboreira e é muito utilizado pelas pessoas na sua alimentação. É constituída maioritariamente por água, cerca de $90 \%$ da sua constituição total. Também é constituída por outros nutrientes como o caroteno e vitaminas e minerais como o cálcio, o fósforo e o ferro.

O método utilizado para calcular a percentagem de água no legume, foi a evaporação, com o auxílio de um microondas. $O$ processo experimental consistiu em aquecer a amostra de abóbora, registar a sua massa, de minuto a minuto, com o microondas ligado sempre na mesma potência, até se verificar libertação de fumo do mesmo.

Deste modo verificou-se que quando a abóbora é aquecida, seca e reduz significativamente de tamanho, o que evidencia que há perda de água.

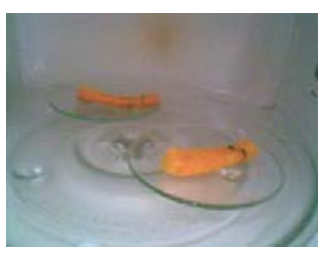

The pumpkin is an orange vegetable, that grows from the pumpkin and it is very used by people in their food. The pumpkin is mainly constituted by water, about $90 \%$ of its total constitution. It is also constituted by other nutrients like carotene, and vitamins and minerals like calcium, phosphorous and iron. The method that was used to calculate the percentage of water in the vegetable was the evaporation, with a microwave. The experimental process consisted on heat the pumpkin sample; write down its mass, every minute, with the microwave always connected on the same power, until the microwave starts to release smoke.

From this way, it was checked when the pumpkin is heated, it dries and gets smaller and that means there is a release of water.

Através das medições efectuadas foi possível calcular a massa de água perdida, em média, por minuto, mesmo tendo em conta que a perda de água ao longo do aquecimento não foi regular. A média foi de 3,236 g por minuto.

Com os valores da massa da abóbora foi também possível calcular a percentagem de água existente na abóbora. Assim, concluí que a abóbora utilizada era aproximadamente $91 \%$ constituída por água, o que significa que em $100 \mathrm{~g}$ de abóbora, 91 g são água. Comparando, depois o valor literário (90\%) com o valor experimental (91\%), verificou-se que o

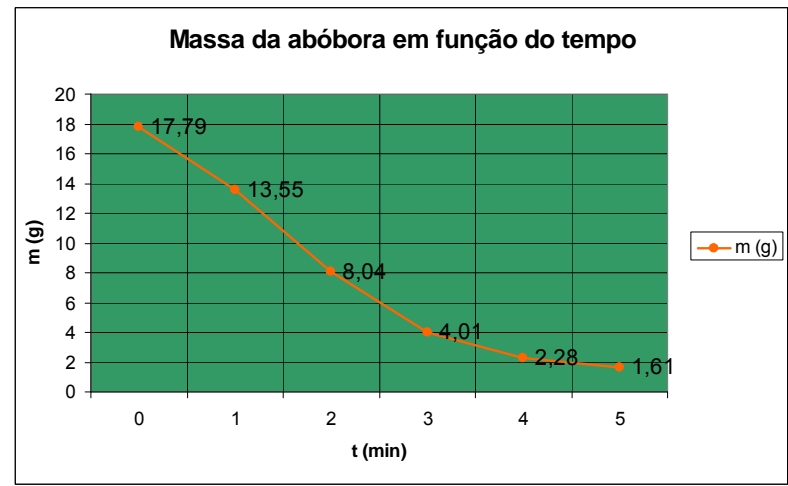

valor achado afastou-se $1 \%$ do valor teórico que pesquisei na Internet e consta na bibliografia. Comprovei assim, que o método utilizado durante esta experiência foi adequado pois obtive um valor bastante exacto.

Bibliografia:

Vaqueiro (2007) - Abóbora [consultado em 2007-11-24], disponível na WWW: <URL:

/http://www.vaqueiro.pt/glossarios/ingredientes_detail.aspx?id=62>.

- Sociedade do Sol (2003) - Projecto ASBC [consultado em 2007-11-24], disponível na WWW:<URL:/ http://www.sociedadedosol.org.br/dicas/dicas 03.htm>. 